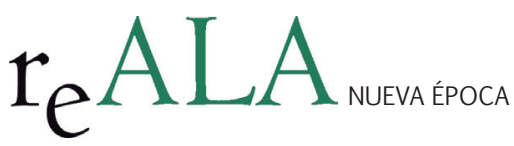

REALA, n 3, enero-junio 2015 ISSN: 1989-8975

DOI: http://dx.doi.org/10.24965/reala.voi3.10249

\title{
Relaciones de puestos de trabajo. ¿Reglamento o acto administrativo? STS de 05 de febrero de 2014 (JUR 2014|1572)
}

\author{
Belén Andrés Segovia \\ Consellería de Gobernación y Justicia, Generalitat Valenciana \\ belen.andres@uv.es
}

\section{Resumen}

La Sentencia que ocupará las siguientes páginas, es objeto de un punto de inflexión a través del cual, el Tribunal Supremo cambia años de doctrina jurisprudencial. La figura por excelencia era el Reglamento en las Relaciones de Puesto de Trabajo. A través de este análisis podremos observar, como los criterios han cambiado, y ya no es el régimen normativo a seguir según el Tribunal Supremo. Para terminar realizaremos un análisis a modo de conclusiones extraídas a raíz de su régimen comparativo con la figura jurídica anterior.

Palabras clave

Función Pública, acto administrativo plúrimo, reglamento, Administración General del Estado, Comunidades Autónomas.

\section{Lists of jobs. Regulation or administrative action? STS February 5, 2014 (JUR $2014 \backslash 1572$ )}

\footnotetext{
Abstract

The Sentence analyzed a turning point through which the Supreme Court changed years of jurisprudence. The figure par excellence was the Regulation on Workplace Relations. Through this analysis we can see, the criteria have changed, and is no longer the regulatory regime to follow according to the Supreme Court. Finally make an analysis by way of conclusions drawn following its comparative legal regime with the previous figure.

Keywords

Public service, administrative act, regulations, Central State Administration, autonomous community.
} 


\section{ANTECEDENTES DE HECHO}

La sentencia de 5 de febrero de 2014', de la que sido ponente el magistrado Vicente Conde, resuelve el recurso planteado por Don Mauricio, funcionario de la Administración Pública, contra la sentencia del Tribunal Superior de Justicia de Madrid de 12 de abril de 2012 (recurso 484/2012)². Por la misma, se desestimó el recurso administrativo3 que el mismo interpuso contra un acuerdo de la Comisión Ejecutiva de la Comisión Interministerial, de fecha 24 de octubre de 2002. Como consecuencia del mismo, se modificó la Relación de Puestos de Trabajo (en adelante RPT) de personal funcionario de las Gerencias del Catastro.

La resolución recoge que, desde su introducción en la Ley de 1984, las Relaciones de Puestos de Trabajo han planteado dificultades jurisprudenciales, que ha sido en cuanto a la caracterización jurídica de esta figura "insegura y no siempre coherente". El lastre que ha supuesto durante años esta figura a efectos de seguridad jurídica, queda de forma explícita expuesta en cuanto a su condición se refieren a las RRPPT de la Administración del Estado y organismos dependientes, pero no a las administraciones de las Comunidades Autónomas y de las entidades locales. En este segundo supuesto, deberá estarse como factor principal para cualquier posible análisis a lo que disponga la Ley de Función Pública de cada Comunidad Autónoma. Asimismo los magistrados señalan que la RPT "no es un acto ordenador, sino un acto ordenado, mediante el que la Administración se auto-organiza, ordenando un elemento de su estructura como es el del personal integrado en ella". Tras su argumentación, indica que la RPT es un acto administrativo, y no una disposición general, por lo que no cabe su apertura a la casación. Por ello, declara no haber lugar al recurso planteado por el funcionario.

La sentencia cuenta con el voto particular de dos de los seis magistrados de la Sección Séptima de la Sala de lo Contencioso, que la ha dictado. Nicolás Maurandi y Pablo Lucas Murillo de la Cueva discrepan de sus compañeros y consideran que la interpretación ahora abandonada por el Supremo -que asimilaba las RRPPT a disposiciones generales- era "más respetuosa con el derecho de los empleados públicos a la tutela judicial efectiva de sus derechos e intereses legítimos". Añaden en este supuesto, que con el giro jurisprudencial que se da ahora queda excluida tanto el acceso a la casación de las sentencias pronunciadas sobre ellas, como su posible impugnación indirecta. Adviértase que a pesar de todo, para estos dos magistrados, no cabe reducir las RRPPT a la condición de acto administrativo aunque tampoco quepa equipararlas plenamente a disposiciones generales. Así pues, de acuerdo con lo expuesto, entienden, en contra de sus compañeros, que su no clasificación en ninguna de esas categorías tradicionales no entrañaba inseguridad jurídica.

\section{DOCTRINA JURISPRUDENCIAL}

La Sala de lo Contencioso-Administrativo del Tribunal Supremo ha dictado la Sentencia de 5 de febrero de 2014, en la que modifica su doctrina sobre la consideración jurídica de las Relaciones de Puestos de Trabajo (RRPPT) de la Administración del Estado y los organismos directamente dependientes de la misma. La clave del sistema de ordenación del personal son las relaciones con los puestos de trabajo o instrumentos organizativos similares llevados al efecto. Por ello, más prudentemente la Ley de Medidas de 1984, trato el tema con menor ambición. De modo que el problema no es tanto su regulación como calificar las relaciones de puestos de trabajo. La Ley de Reforma de la Función Pública, en su artículo 154, introdujo este instrumento de ordenación de las estructuras burocráticas basado en las tradicionales plantillas orgánicas. Dicha Ley no obliga a una descripción pormenorizada de las tareas, cometidos y responsabilidades correspondientes a cada puesto, limitando los contenidos de las relaciones de los puestos de trabajo a una enumeración de éstos, precisando el tipo de empleado, funcionario, laboral o eventual que ha de ocuparlo, así como el sistema de provisión o libre disposición o concurso, los requisitos

\footnotetext{
1 Sentencia del Tribunal Supremo (Sala de lo Contencioso-Administrativo, Sección7ª) de 5 de febrero 2014. (RJ 2014/1572)

2 Sentencia Tribunal Superior de Justicia de Madrid, (Sala de lo Contencioso-Administrativo, Sección7 ${ }^{\mathrm{a}}$ ), núm. $484 / 2012$ de 12 abril (JUR 2012|231119).

3 El Tribunal Superior de Justicia de Madrid dictó sentencia de 12 de abril de 2012 en el recurso administrativo núm. $2825 / 03$. Antecedente de hecho primero de la Sentencia del Tribunal Supremo (Sala de lo Contencioso-Administrativo, Sección7 ${ }^{\mathrm{a}}$ ) de 5 febrero 2014. (RJ 2014|1572).

4 Ley 30/1984, de 2 de agosto, de medidas para la reforma de la Función Pública (Vigente hasta el 01 de Enero de 2015) señala en su artículo 15 la regulación de las Relaciones de Puestos de Trabajo de la Administración del Estado, de modo que, en su apartado primero expone que, "las relaciones de puestos de trabajo de la Administración del Estado son el instrumento técnico a través del cual se realiza la ordenación del personal, de acuerdo con las necesidades de los servicios y se precisan los requisitos para el desempeño de cada puesto en los términos siguientes: a) Las relaciones comprenderán, conjunta o separadamente, los puestos de trabajo del personal funcionario de cada Centro gestor, el número y las características de los que puedan ser ocupados por personal eventual así como los de aquellos otros que puedan desempeñarse por personal laboral". Y el apartado b) que tras su modificación por la Ley 62/2003, de 30 de diciembre, de medidas fiscales, administrativas y del orden social, queda redactado del siguiente modo: “b) Las relaciones de puestos de trabajo indicarán, en todo caso, la denominación, tipo y sistema de provisión de los mismos; los requisitos exigidos para su desempeño; el nivel de complemento de destino y, en su caso, el complemento específico que corresponda a los mismos, cuando hayan de ser desempeñados por personal funcionario, o la categoría profesional y régimen jurídico aplicable cuando sean desempeñados por personal laboral".
} 
para su desempeño, el nivel del complemento de destino y, en su caso, el complemento específico que corresponda a los mismos, cuando hayan de ser desempeñados por personal funcionario, o la categoría profesional, régimen jurídico aplicable cuando sean realizados por personal laboral, así como, los puestos de trabajo de provisión indistinta, por no estar reservados a determinados cuerpos de funcionarios.

Aunque es cuestionable que la mera enumeración de puestos de trabajo tenga un carácter normativo, es innegable que una abundante jurisprudencia le atribuyó previamente su carácter de reglamentario. Objeto de esta expresiva tendencia es la Sentencia del Tribunal Supremo de 25 de abril de 1995 (RJ 1995, 3397)5, que citando a otras anteriores considera:

“Es jurisprudencia consolidada de esta Sala (v. gr. SSTS 14 diciembre 1990 [RJ 1990|10163], 14 julio 1993 [RJ 1993/5641] y 28 noviembre 1994 [RJ 1994/9332]) que las relaciones de puestos de trabajo aprobadas por las Administraciones Públicas en ejercicio de sus potestades organizatorias tienen naturaleza normativa, atendido su carácter ordinamental y las notas de generalidad, abstracción y permanencia que en ellas concurren, diferenciándolas de los actos con destinatario plural e indeterminado pero carentes de contenido normativo"6.

Esta tendencia jurisprudencial ha sido, modificada o, en sus preceptos matizada por la Sentencia del Tribunal Supremo de 12 de noviembre de 2008 (RJ 2008, 7880$)^{7}$, que limita el alcance a su supuesta naturaleza reglamentaria en los términos expuestos por la misma:

“(...) si bien este Tribunal ha atribuido a los acuerdos sobre regulación de la RPT, a veces, la naturaleza de normas, ello lo ha sido a los solos efectos de admisibilidad de la casación, o en algún caso excepcional cuando la regulación o modificación de la RPT se contiene en un instrumento jurídico, que por su forma de exteriorización, procedimiento de elaboración y modo de publicación, e incluso por su contenido añadido, justifica que se le asigne esa naturaleza reglamentaria. Lo que no consta que sea el caso de autos"8.

De esta circunstancia nace el hecho de que, la posibilidad de que un particular pueda articular la solicitud de la revisión de oficio vía artículo 102.2 LRJ-PAC, sea una cuestión abierta9. Esta línea de argumentación es desvirtuada por un inminente cambio de rumbo jurisprudencial que nos la ofrece la Sentencia del Tribunal Supremo de 4 de diciembre de 2013 (Rec. 1260/2012) (10 $^{\circ}$ cuando dispone,

“CUARTO.- En la casación núm. 2986/2012 esta Sala ha planteado a las partes la posible inadmisibilidad de un recurso de casación contra una sentencia dictada en una relación de puestos de trabajo, sobre la base de que pudiese concluirse que no procede otorgarles la consideración de disposición general. Lo cual impone aclarar, al igual que se ha hecho en nuestra reciente sentencia de 30 de octubre de 2012 (casación núm. 3105/2012), que en tanto se decide la anterior cuestión, bien confirmando el criterio hasta ahora seguido de atribuir aquella consideración a las relaciones de puestos de trabajo para franquear el acceso a la casación de las sentencias que las enjuicien, bien variándolo, debe continuar aplicándose, como aquí se hace, la solución hasta ahora seguida. ${ }^{11}$

Este punto se puede destacar observando, que pese a que el Supremo confirme la situación por la que se declara la "apertura y vía libre a la casación", no es garantía de que en el caso de que la Sala, planteara de oficio la posible inadmisibilidad del recurso de casación por tratarse de las Relaciones de Puestos de Trabajo, quedaran desprovistas de la misma tras su paso por las Salas de lo Contencioso-Administrativo.

Resulta especialmente llamativo que el Tribunal Supremo quisiera alterar el régimen de garantías del instrumento más potente de la Administración: las Relaciones de Puestos de Trabajo. Esto es así debido a que, un posible debilitamiento de su potestad de control, llevado a cabo por la amplísima discrecionalidad inherente a la potestad de autoorganización, quedaba bajo la sujeción de una posible desaparición de la garantía de la segunda

5 Sentencia del Tribunal Supremo (Sala de lo Contencioso-Administrativo, Sección $7^{\text {a }}$ ), de 25 abril 1995, (RJ 1995|3397). Fundamento de Derecho segundo.

6 Sentencia del Tribunal Supremo de 25 abril 1995, Fundamento jurídico segundo, (RJ 1995|3397).

7 Sentencia del Tribunal Supremo (Sala de lo Contencioso-Administrativo, Sección7 ${ }^{\mathrm{a}}$ ) de 12 noviembre 2008 ( $R \mathrm{~J} 2008 \mid 7880$ ).

8 Sentencia del Tribunal Supremo de 12 noviembre 2008 (RJ 2008|7880). Fundamento jurídico tercero.

9 DOMINGO ZABALLOS, Manuel José (2010a), ESCUÍN PALOP, Vicente (2010b), Impugnación y revisión de la actividad de los Entes Locales (Teoría y práctica): 81-82.

10 Sentencia del Tribunal Supremo (Sala de lo Contencioso-Administrativo, Sección $7^{\text {a }}$ ) de 4 diciembre 2013, (RJ 2014|293).

11 Sentencia del Tribunal Supremo de 4 diciembre 2013, Fundamento jurídico cuarto, (RJ 2014|293). 
instancia ante el Supremo. Sin embargo, la misma supone una medida de inadmisibilidad de los recursos de casación contra las RPT, que pueda esbozar su desarrollo más allá de su calificación reglamentaria. No eran escasas las ocasiones por las que tal recurso de casación, era objeto de coartada y argucia de la Administración a fin de prolongar la vigencia de Relaciones de Puestos de Trabajo declaradas nulas por sentencias de las Salas, en tanto se resolvía el recurso de casación.

Durante dicho transcurso, no se aplican medidas cautelares al respecto, por lo que la RPT seguía aplicándose, y consecuentemente, la Administración tenía la potestad de consolidar dichas situaciones ilegales. En suma, ante tal exposición es objeto de valoración, el abuso de la posibilidad de tal recurso de casación para fines políticos, cuya dilación en el tiempo, justificaba en el tiempo su existencia. A ello debemos añadir el importante dato de que la ejecución de las sentencias que invalidan las RPT operan sobre un rigoroso tejido burocrático, de modo que frente a los autos dictados en ejecución, cabe recurrir en una casación adicional, la dilatación del proceso era patente en el tiempo, hasta que la Administración admitía la aprobación de una nueva RPT que permitía el acceso a otra nueva dinámica impugnatoria.

Llegados a este punto se estima por la doctrina jurisprudencial que las RPT, muestran su posible impugnación como si se tratase de reglamentos sui generis que deben merecer el recurso de casación. Con ello, se gana en seguridad jurídica, se evitan los posibles fraudes procesales, y las RPT son objeto de cosa juzgada con una mayor celeridad, a sensu contrario de la figura que envuelve a los actos administrativos. Muy contrario de lo que sucede en la Sentencia del Tribunal Supremo de 5 de febrero de 2014 (recurso número 2986/2012 modifica su doctrina sobre la consideración jurídica de las Relaciones de Puestos de Trabajo (RRPPT) de la Administración del Estado (AGE) y los organismos directamente dependientes de la misma. Afirma el Tribunal Supremo, con objeto de terminar con la opacidad que envuelve su concepto, en cuanto a si se refiere a un acto administrativo plúrimo o un reglamento que:

"Sobre esa base, y en la alternativa conceptual de la caracterización como acto administrativo o como norma, entendemos que lo procedente es la caracterización como acto, y no como norma o disposición general. Tal caracterización como acto, según se ha expuesto antes, es por lo demás la que ha venido proclamándose en la jurisprudencia (por todas reiteramos la cita de las sentencias de 19 de junio de 2006 y la de 4 de julio de 2012 [RJ 2012, 7710] y 10 de julio de 2013 [RJ 2013, 6154]), aunque lo fuera en referencia al plano sustantivo, al diferenciarlo del procesal." $\mathrm{Y}$ en tal caso prosigue mencionando que "en la referida Sentencia de 19 de Junio de 2006 (RJ 2006, 3770) (F.D. $3^{\circ}$ ) ya se afirmaba respecto de las RRPPT la falta "de la nota de generalidad y demás caracteres propios de las disposiciones reglamentarias". En esa misma línea argumental de falta "de la nota de generalidad y demás caracteres propios de las disposiciones reglamentarias se insiste" se insiste en la Sentencia de 4 de julio de 2006 (RJ 2006, 3753) -Recurso de casación 3422/2001, F.D. $2^{\circ}$-; y en las de 4 de Julio de 2012 (RJ 2012, 7710) -Recurso de casación 1984/2010, F.D. $5^{\circ}$-; de 10 de julio de 2013 (RJ 2013, 6154) -Recurso de casación n 2598/2012, F.D. $4^{\circ}$-, en las que se expone la problemática línea evolutiva de la jurisprudencia. Es criterio asentado en la doctrina y en la jurisprudencia, para la distinción entre el acto y la norma, el que se centra en la consideración de si el acto de que se trate innova o no el ordenamiento jurídico, integrándose en él, con carácter general y abstracto, y siendo susceptible de ulteriores y sucesivas aplicaciones; o si se trata de un acto ordenado que no innova el ordenamiento, sino que es un acto aplicativo del mismo, en cuya aplicación se agota la eficacia del acto. Sobre esa base conceptual, y en línea con la doctrina de las sentencias que se acaban de citar, entendemos que la RPT no es un acto ordenador, sino un acto ordenado, mediante el que la Administración se autoorganiza, ordenando un elemento de su estructura como es el del personal integrado en ella"12.

Pese a que la sentencia no pretende extender sus efectos a las Comunidades Autónomas se puede observar que, salvo configuración normativa diferente por sus leyes de función pública, que en la actualidad es inexistente en cuanto a sus instrumentos ordenadores, ya que sin perjuicio de su delegación en órganos inferiores, la competencia de su aprobación y modificación corresponde, de ordinario, al consejo de gobierno; y en las corporaciones locales la competencia se le atribuye al pleno, salvo a los municipios de gran población, que le correspondería a la junta de gobierno ${ }^{13}$. En consecuencia, a efectos jurisdiccionales, las Relaciones de Puestos de Trabajo se consideran disposiciones administrativas recurribles, como los actos dictados en su aplicación.

12 Sentencia del Tribunal Supremo (Sala de lo Contencioso-Administrativo, Sección7 $7^{\text {a }}$ ) de 5 febrero 2014, Fundamento Jurídico tercero. (RJ 2014|1572)

13 PARADA VÁZQUEZ, Ramón (2012): 468-470. 
En conclusión, pese a la fructuosa doctrina que durante años se ha pronunciado a favor del reglamento como figura que envuelve las RTP, con la Sentencia del Tribunal Supremo de 5 de febrero de 2014, se da un cambio jurisprudencial de criterio, de forma que las RRPPTT quedan degradadas por el Tribunal Supremo a simples actos administrativos generales, en aquellos casos que afecten a la Administración General del Estado.

\section{COMENTARIO}

\section{Un breve apunte sobre la incorporación del personal laboral a la Administración}

Hasta entrado el año 1964 podía considerarse que existía un monopolio funcionarial en la Administración. Para mejor entender, todo funcionario que prestaba sus servicios en ella, era considerado funcionario público, y por tanto, se encontraba sometido a una serie de normas de carácter unilateral, por leyes y reglamentos administrativos. Con la entrada en vigor de la Ley de Funcionarios Civiles del Estado de 1964, que cambió la conceptualización que se tenía hasta la fecha y que permitió por vez primera, en el ordenamiento administrativo español, la dualidad de regímenes jurídicos en la Administración al permitir la contratación de personal laboral y además, con carácter discrecional ${ }^{14}$.

A pesar de sus esfuerzos por regular esta materia, en el Decreto 315/1964 de 7 de febrero, no figuraba ninguna definición ni establecía, ningún criterio orientador para su contratación. Su incorporación era objeto de un importante grado de flexibilidad, de modo que evitaba el encorsetamiento que suponían las normas funcionariales. El hecho de que en esta ley se definiera el concepto de funcionario pero no se dijera nada del personal laboral, ni se establezcan las bases ni ningún tipo de criterio decisivo, ha sido una de las principales causas de los numerosos problemas y disfunciones surgidas con posterioridad' ${ }^{15}$. Ante tal confusión, el dictamen del Consejo de Estado de 14 de diciembre de 1960 que concibió como una "técnica administrativa", contribuyo a la opacidad regulatoria, y en consecuencia se reconoció un amplio margen a la Administración en el momento de ejecutar su decisión ${ }^{16}$.

Llegados a este punto, ante tal inseguridad normativa, se recogieron estos postulados en la formulación originaria del artículo 15 de la Ley 30/1984, de 2 de agosto, de medidas para la reforma de la Función Pública, por la cual se extendió considerablemente la presencia del personal laboral en la Administración con un precepto hasta entonces desconocido, donde el aspecto más decisivo de laboralización fue la redacción originaria del artículo 15.1.c) ${ }^{17}$. Para mejor entender, al regular el contenido de las nuevas relaciones de puestos de trabajo de la Administración del Estado establecía que todos sus requisitos serían establecidos por el Ministerio de Presidencia, a propuesta de los Ministerios que en tal caso sean competentes en la materia "debiendo especificarse aquellos puestos que, atendiendo a la naturaleza de su contenido, se reservan a funcionarios públicos". Tras este desafortunado inciso, se entendía que a partir del momento de tal regulación, la figura principal iba a ser el personal laboral y la excepción, los funcionarios públicos ${ }^{18}$.

14 El artículo $7 .^{\circ}$ del Decreto 315/1964 de 7 de febrero en desarrollo de la Base I de la Ley 109/1963:

“1. Son trabajadores al servicio de la Administración civil los contratados por ésta con dicho carácter, de acuerdo con la legislación laboral, que les será plenamente aplicable.

2. En todo caso, la admisión de trabajadores al servicio de la Administración civil deberá estar autorizada reglamentariamente."

16 Dictamen del Consejo de Estado de 14 de diciembre de 1960 “El régimen administrativo y laboral son técnicas de organización que pueden ser utilizadas indistintamente por la Administración en la configuración de la relación jurídica con los grupos y categorías del personal a su servicio".

17 Artículo 15.c) de la Ley 30/1984, de 2 de agosto, de medidas para la reforma de la función pública.

"Con carácter general, los puestos de trabajo de la Administración del Estado y de sus Organismos Autónomos así como los de las Entidades Gestoras y Servicios Comunes de la Seguridad Social, serán desempeñados por funcionarios públicos.

Se exceptúan de la regla anterior y podrán desempeñarse por personal laboral:

los puestos de naturaleza no permanente y aquellos cuyas actividades se dirijan a satisfacer necesidades de carácter periódico y discontinuo;

- los puestos cuyas actividades sean propias de oficios, así como los de vigilancia, custodia, porteo y otros análogos;

- los puestos de carácter instrumental correspondientes a las áreas de mantenimiento y conservación de edificios, equipos e instalaciones, artes gráficas, encuestas, protección civil y comunicación social, así como los puestos de las áreas de expresión artística y los vinculados directamente a su desarrollo, servicios sociales y protección de menores;

- los puestos correspondientes a áreas de actividades que requieran conocimientos técnicos especializados cuando no existan Cuerpos o Escalas de funcionarios cuyos miembros tengan la preparación específica necesaria para su desempeño, y

los puestos de trabajo en el extranjero con funciones administrativas de trámite y colaboración y auxiliares que comporten manejo de máquinas, archivo y similares.

- los puestos con funciones auxiliares de carácter instrumental y apoyo administrativo". 
Muchos de los problemas planteados por el artículo 15 podían haberse solucionado si el legislador de 1984 hubiera establecido algún tipo de criterio que hubiera podido perfilar una línea divisoria clara entre ambos colectivos, personal laboral y funcionarios. Ello ha supuesto que a día de hoy, nos podamos encontrar en las Relaciones de Puesto de Trabajo situaciones tan paradójicas como que en unas Administraciones un puesto de trabajo se oferta para un laboral, mientras que en otras, esas mismas funciones vienen desempeñadas por personal funcionarial.

El precepto fue impugnado ante el Tribunal Constitucional en la medida en que presuntamente vulneraba la reserva de ley establecida en el artículo 103.3 de la Constitución al otorgar al Ministerio de Presidencia la competencia para especificar los puestos de trabajo que se reservaban a los funcionarios públicos. En esta línea la Sentencia del Tribunal Constitucional de 11 de junio de $1987^{19}$, por el que se declara inconstitucional el citado precepto y establece que "Este apoderamiento indeterminado que la Ley confería al Ministerio de la Presidencia, a efectos de especificar cuáles sean los puestos de trabajo que deban quedar reservados a funcionarios públicos, entraña una patente conculcación de la reserva de Ley establecida en el art. 103.3 de la Constitución y, de este modo, una plena renuncia del legislador a su tarea de establecer en este punto, ciertamente crucial para la estructura de las Administraciones Públicas y de la propia Función Pública, condiciones y límites materiales sobre las determinaciones concretas que puedan ser adoptadas por los órganos de la Administración. Tal necesario encuadramiento legislativo de las decisiones de quienes hayan de aplicar o desarrollar las propias normas de la Ley no viene dado en este precepto, desde luego, por su mención, como pretendido criterio para las decisiones sobre esta reserva de puestos de trabajo, a «la naturaleza de su contenido» propio, imprecisa referencia que no vincula efectivamente a la decisión administrativa. Este último inciso del art. 15.1 («debiendo especificar aquellos puestos que, en atención a la naturaleza de su contenido, se reservan a funcionarios públicos») es inconstitucional y ha de ser declarado nulo"20. Declarándose asimismo, "corresponde sólo a la Ley la regulación del modo de provisión de puestos de trabajo al servicio de las Administraciones Públicas, pues no otra cosa se desprende de la opción genérica de la Constitución (arts. 103.3 y 149.1.18) en favor de un régimen estatutario para los servidores públicos y de la consiguiente exigencia de que las normas que permitan excepcionar tal previsión constitucional sean dispuestas por el legislador, garantizándose, de este modo, una efectiva sujeción de los órganos administrativos, a la hora de decidir qué puestos concretos de trabajo puedan ser cubiertos por quienes no posean la condición de funcionario" ${ }^{21 .}$

En definitiva, con esta sentencia se clarifica que la opción del Tribunal Constitucional tiende a dar un mayor respaldo a la opción funcionarial. Cabe matizar al respecto, que corresponde al propio legislador y no al Gobierno, la determinación de los puestos de trabajo que pueden ser ocupados por empleados sometidos al Derecho Laboral. Sin embargo, más recientemente, la jurisprudencia del Tribunal Supremo parece estar realizando una interpretación bastante más restrictiva de estos supuestos. Así en la Sentencia del Tribunal Supremo de 9 de julio de $2012^{22}$, a propósito de la naturaleza de un puesto de trabajo de auxiliar administrativo que tenía encomendadas las funciones de apoyo en la realización de tratamientos de textos, cálculo, fotocopias, fax y recepción de llamadas telefónicas, dirá el tribunal que en caso de duda entre la naturaleza funcionarial o laboral del puesto, "habrá de efectuarse una interpretación que tenga en cuenta cuáles son las notas fundamentales que se toman en consideración en el conjunto de esos casos que directamente son enumerados en el tan repetido precepto como hábiles para encarnar la excepción. Y estas notas son algunas de las siguientes: la temporalidad del puesto; su contenido coincidente con actividades propias de oficios o profesiones existentes en el sector privado, lo que equivale a señalar que se trata de puestos que no difieren en nada con los que puedan existir en dicho sector; su carácter instrumental en todo lo relativo a edificios y demás medios materiales de la Administración; o su carácter siempre secundario, auxiliar o de mera colaboración cuando tengan asignadas funciones administrativas" ${ }^{\prime 3}$

Finalmente ha considerado que dicho puesto tenía naturaleza funcionarial al asimilarse sus tareas a las asignadas a la Escala de Auxiliares Administrativos. Siendo de este modo, dirá el Tribunal que "no cabe atribuírselas a personal laboral. Debe tenerse en cuenta en este sentido que las funciones auxiliares instrumentales y de apoyo administrativo a las que se refiere el artículo 15.1 c) de la Ley 30/1984 no pueden ser las que ya desempeñan cuerpos o escalas funcionariales. El auxilio instrumental y el apoyo administrativo se sitúan fuera de los cometidos de aquéllos, de ahí la calificación que les da la Ley que contempla factores externos a los propiamente administrativos, es decir, hace hincapié en lo que no son actividades de naturaleza administrativa para aceptar que puedan ser encomendadas a personal laboral"24.

19 Sentencia del Tribunal Constitucional (Pleno), núm. 99/1987 de 11 junio, (RTC 1987l99).

20 Sentencia del Tribunal Constitucional núm. 99/1987 de 11 junio, Fundamento Jurídico Tercero.

21 Sentencia del Tribunal Constitucional núm. 99/1987 de 11 junio, Fundamento Jurídico Octavo.

22 Sentencia del Tribunal Supremo (Sala de lo Contencioso-Administrativo, Sección7 ${ }^{\text {a }}$ ) de 9 julio 2012, (RJ 2012|7790).

23 Sentencia del Tribunal Supremo de 9 julio 2012, Fundamento jurídico cuarto (RJ 2012|7790).

24 Sentencia del Tribunal Supremo de 9 julio 2012, Fundamento jurídico tercero (RJ 2012|7790). 


\section{La categoría jurídica de las Relaciones de Puestos de Trabajo ¿Potestad reglamentaria o Acto Administrativo Plúrimo?}

El Estatuto Básico del Empleo Público describe la figura de las Relaciones de Puesto de Trabajo en su artículo 74 del EBEP, como aquellas en que se agrupan los puestos en función de sus características a fin de ordenar la selección, la formación y la movilidad funcionarial. Las relaciones de puestos de trabajo comprenderán al menos, la denominación de los puestos, los grupos de clasificación profesional, los cuerpos o escalas, en su caso, a que estén adscritos, los sistemas de provisión y las retribuciones complementarias ${ }^{25}$. Dichos instrumentos serán públicos. Este marco conceptual viene justificado para mejor entender, en la Sentencia del Tribunal Supremo de 5 de febrero de 2014 sobre las Relaciones de Puestos de Trabajo, donde nuevamente se cuestiona si nos encontramos ante actos generales o actos normativos reglamentarios.

En efecto, el Derecho Administrativo es un mecano complejo. Bajo la vieja Ley de Jurisdicción ContenciosoAdministrativa de 1956 la potestad de control se ejercía a través del acto administrativo y del reglamento ${ }^{26}$. Sin embargo, tras la Ley Reguladora de la Jurisdicción Contencioso-Administrativa se cita un tratamiento que da lugar a una actuación administrativo (art. 25 de la Ley 29/98) para dar cobertura a cuatro conceptos: un acto expreso, desestimación presunta, inactividad y finalmente la vía de hecho, manteniéndose a su vez la figura reglamentaria. Pero sutilmente, en medio de este desmembramiento conceptual, aparece una nueva figura que son los denominados "actos plúrimos" o actos generales y que a su vez crean otros actos generales de perfil más singular: las Relaciones de Puestos de Trabajo, es decir, se debate entre ser un poco más que acto general pero menos que un reglamento. Y esta naturaleza ambigua justifica los problemas a la hora de determinar la naturaleza de esta figura vía jurisprudencial.

Recapitulemos brevemente las aportaciones que ha conllevado la existencia de los actos plúrimos. Se debaten en los términos en los que está siendo planteada esta figura de forma que se exige, que el acto administrativo que es recurrido indirectamente carezca de vicio alguno que no sea adquirido de manera directa de la concreta disposición general de la que deriva. Concurriendo esta condición, la posibilidad de reaccionar contra el acto se contrae a la denuncia de los vicios de la disposición y de ahí la importancia de que la misma no sea declarada consentida calificándola como acto. El matiz, estrictamente procesal, tiene implicaciones materiales evidentes: el acto administrativo que se limita a aplicar una disposición viciada puede ser considerado conforme a derecho -no declarado como tal, porque la Sentencia no entraría a resolver- si se parte de considerar posible la consolidación de la disposición, a pesar de sus vicios, por el mero transcurso del plazo para recurrir. Si el acto se limita a aplicar la disposición viciada pero consolidada, se dirá que hubo que recurrir la disposición en plazo y asunto resuelto. Como hace mención Francisco José Ojuelos Gómez $z^{27}$, “todo ello, gracias a la calificación de una disposición como acto, plúrimo eso sí, con la intención de indicar, sin emplear la denominación "general” la pluralidad de destinatarios. Lingüísticamente, "plúrimo" es un artículo nuevo, que será incorporado a la próxima (vigésima tercera edición del DRAE), que significa abundante o variado". El debate al respecto no ha cesado, resultando que a veces, y sin que en la mayoría de los casos más recientes estudiados se entre en excesivas fundamentaciones, se califica como acto plúrimo a efectos de limitar la posibilidad de accionar contra ella aquella misma resolución que en otros supuestos se entiende revisable.

Un ejemplo del tratamiento jurisprudencial de esta nueva figura en el mundo del derecho es la Sentencia del Tribunal Supremo de 20 de marzo del $2012^{28}$. La Sala fundamenta con todo ello la exclusión de un juicio cumplido sobre la legalidad de las dos Resoluciones recurridas emanadas de la Convocatoria, en clara contradicción con la doctrina constitucional aplicable y que la propia Sala sentenciadora llega a citar, aunque claro, no reproduce: $v$. gr., STC Sala Primera, 107/2003, de 2 de junio de 2003: "En todo caso, conviene asimismo precisar que, conforme a nuestra doctrina (SSTC 1931987, de 9 de diciembre, FJ 2, y, 93/1995, de 19 de junio, FJ4, por todas y ATC 12/1998, de 15 de enero, FJ4, el hecho de que la demandante no recurriera en su día contra la Orden por la que se publicaron las bases de la convocatoria no es obstáculo para plantear ahora, ante este Tribunal, un recurso de amparo por lesión de sus derechos fundamentales contra los actos de aplicación de dichas bases por la razón de que aquellas se consideran inconstitucionales, puesto que la presunta vulneración del derecho fundamental a acceder en condiciones de igualdad a los cargos y empleos públicos (art. 23.2 CE) invocado por la demandante se habría producido, en su caso, de forma concreta y real, en el momento en que el nombramiento para ocupar la plazas controvertidas ha recaído en personas

25 ROQUETA BUJ, Remedios (2012a) y SEVILLA MERINO, Ignacio (2012b): 253-258.

26 BELANDO GARÍN, Beatriz, "Título II (Capítulos 1 y 2)", en la obra: DOMINGO ZABALLOS, Manuel José (2010ª y ESCUÍN PALOP, Vicente $\left(2010^{b}\right)$, Impugnación y revisión de la actividad de los Entes Locales (Teoría y práctica). Pamplona, Civitas, Thomson Reuters, p. 143.

27 OJUELOS GÓMEZ, Francisco José (2014), “El acto administrativo “Plúrimo”. Consecuencias jurídico-procesales de su existencia”, Blog jurídico Crítica procesal y sustantiva. Fecha de publicación: 8 de octubre de 2013. Enlace de la publicación: http://criticaprocesal.blogspot. com.es/2013/10/procesal-contencioso-administrativo-el.html. Fecha de visita: 12.06.2014, 14.33 p.m.

28 Sentencia del Tribunal Supremo (Sala de lo Contencioso-Administrativo, Sección7ª) de 20 de marzo 2012. (RJ 2012/4682) 
distintas a la recurrente en amparo, esto es, al dictarse la Resolución de 24 de septiembre de 1999 de la Secretaría de Estado para la Administración pública, por la que se nombran funcionarios de carrera del cuerpo auxiliar de la Administración de la Seguridad Social mediante el proceso de consolidación de empleo de carácter temporal, que es el acto administrativo contra el que se dirigió el recurso contencioso-administrativo desestimado por la Sentencia que ahora se recurre en amparo". Finalmente, la STS que resuelve el recurso acaba estimándolo, en gran medida, en base a dicha doctrina, aunque no se cite expresamente.

Los estudios que han ahondado en el tratamiento del problema concluyen, que es una figura bien irrelevante, bien irresoluble. Para la doctrina más actual y para los Altos Tribunales no siempre es posible determinar qué es acto "plúrimo" y qué disposición general; para la doctrina, ello sucede porque los criterios diferenciadores son divergentes. En el caso de los Tribunales, para un mismo tipo de resolución de la administración, han cambiado su propio criterio, calificándolo a veces como acto y a veces como disposición.

Una vez analizada la figura del acto plúrimo, y sin entrar en consideraciones ni juicios de valor que nos desvíen de su concepto, las Relaciones de Puestos de Trabajo son una especie de "plantilla enriquecida" que muestra todos los efectivos del ejército burocrático, tanto los existentes como los que se necesitan ${ }^{29}$. Así, la Relación de Puestos de Trabajo es un documento llamado a relacionar o detallar los puestos de trabajo de personal funcionario y los de personal laboral (una RPT para cada colectivo) ${ }^{30}$.

La Administración autonómica, por su parte lleva años escudándose en el ingenio procesal a fin de evitar un enjuiciamiento de fondo, donde la RPT es calificada bajo la figura de un reglamento, y por lo tanto, el plazo para impugnar disposiciones que la misma comprende es de dos meses tal y como indica el art. 46.1 de la Ley Reguladora de la Jurisdicción Contencioso-Administrativa. Frente a esta regulación, la figura del acto administrativo, viene representada en el apartado 2 del artículo 26 de la Ley 30/92 donde incide, para mayor claridad al respecto de la intención del Legislador, en la intrascendencia a los efectos del recurso indirecto del transcurso del plazo para recurrir la disposición general e, incluso, de la desestimación de un recurso indirecto anterior interpuesto contra la propia disposición, consagrando pro actione por tanto, una suerte de derogación de la exceptio rei iudacatae. Cabe destacar ahora, por su trascendencia posterior en las conclusiones de este trabajo, que en la regulación expresa de la cuestión de legalidad prevista en el artículo 27.1, contenida en los artículos del 123 al 126 LJCA, el Legislador emplea (123.1) la expresión preceptos reglamentarios y no, disposición general.

Los fines de este estudio exigen igualmente invocar el artículo 53.2 de la LRJ-PAC que, como exigencias concurrentes para la conformidad a derecho de los actos, establece su necesario ajuste a las normas jurídicas más (y) su determinación y adecuación a los fines del propio acto: El contenido de los actos se ajustará a lo dispuesto por el ordenamiento jurídico y será determinado y adecuado a los fines de aquéllos. En principio, y excluidos evidentemente los actos de trámite, contra los que no cabe reacción jurídica más allá de los supuestos referidos en artículo 25.1 de la LJCA, cuya naturaleza específica es propiciar las condiciones para el dictado de otros, el dictado de actos con fundamento en otros actos debería limitarse a los supuestos que pueden extraerse de una interpretación conjunta del citado artículo 53.2 de la Ley 30/92, de 26 de noviembre, del artículo 106.1 de la Constitución (Los Tribunales controlan la potestad reglamentaria y la legalidad de la actuación administrativa...) y del artículo 28 de la LJCA, que confirma ex lege la validez de los actos administrativos que, dictados con base en otros, se limitan a reproducirlos o a confirmarlos y, por lo tanto, no tendrían contenido novedoso alguno ${ }^{31}$.

Así pues, la Sentencia de 5 de febrero del 2014 representa el replanteamiento de nuestra precedente jurisprudencia, de modo que, en primer lugar, antes de razonar el referido cambio debemos hacer la advertencia de que las consideraciones que seguirán están directamente referidas solo a las Relaciones de Puestos de Trabajo de la Administración del Estado u organismos directamente dependientes de la misma.

Estas categorías jurídicas son a las que se refiere el art. 15 Ley 30/1984; por lo que no cabe que de modo apriorístico que dichas consideraciones deban ser necesariamente aplicables también a las Relaciones de Puestos de Trabajo de Administraciones de las Comunidades Autónomas y de las Entidades Locales, habida cuenta la derogación de los arts. 16 y 17 de la Ley 30/1984 por la Ley 7/2007 (Disposición Derogatoria Única b²), y de que, en

29 Ejemplo de RPT: Boletín Oficial de La Rioja: Consejería de Administración Pública y Hacienda, Decreto 4/2013, de 18 de enero, por el que se aprueban las Relaciones de Puestos de Trabajo correspondientes a los funcionarios y al personal laboral de la Administración General de la Comunidad Autónoma de La Rioja, núm. 13, p. 1724.

30 Identifica cada puesto con un numerito y un nombre en filas (horizontales) y luego varias columnas (verticales) se dedican para cada puesto a indicar sus complementos retributivos (específico y destino), requisitos, formación, etc.

31 La vinculación positiva o negativa de la Administración a la ley requiere, a nuestro entender, del análisis de los concretos derechos en liza en cada caso. Un tratamiento exhaustivo de la vinculación negativa en ámbito local está disponible en http://www.cemci.org/revista/ numero-8/pdf/articulo2.pdf: La consolidación del principio de vinculación negativa en el ámbito local. GALÁN GALÁN, Alfredo (2010). En la página 20 se expresa, en favor del posicionamiento del Tribunal Supremo, la consideración debida al principio constitucional de Autonomía local.

32 ROQUETA BUJ, Remedios (2012a) y SEVILLA MERINO, Ignacio (2012b): 259-262. 
definitiva, en cualquier intento de categorización de la naturaleza jurídica de las Relaciones de Puestos de Trabajo, u otro instrumento alternativo de ordenación del personal (recuérdese lo dispuesto en el art. 74 Ley 7/2007).

En esta clase de supuestos, deberá estarse como factor principal para cualquier posible análisis a lo que disponga la Ley de la Función Pública de cada Comunidad Autónoma, dentro de los límites marcados al respecto por la legislación básica del Estado (art. 149.1. 18 $\mathrm{CE}$ ) y en concreto los que se derivan en cada caso de lo dispuesto en la Ley 7/2007, del Estatuto Básico del Empleado Público, arts. 3 y 6.

Por último, tal y como menciona el Fundamento jurídico 4 de la referida Sentencia, "sobre esa base conceptual, y en línea con la doctrina de las sentencias que se acaban de citar, entendemos que la RPT no es un acto ordenador, sino un acto ordenado, mediante el que la Administración se autoorganiza, ordenando un elemento de su estructura como es el del personal integrado en ella". Por lo que cabe concluir que, no se pueden impugnar ni recurrir en recurso de casación ante el Tribunal Supremo ninguna RPT de la Administración General del Estado, queda desprovista la posibilidad de obtener una instancia más de recurso al personal público. Dichas relaciones deben conceptuarse " $a$ todos los efectos" como actos administrativos, con la consecuencia de que no cabe contra las mismas el recurso de casación ante el propio Tribunal Supremo.

Ello rectifica la jurisprudencia seguida hasta la fecha, que asimilaba las RPT a disposiciones generales a los efectos del recurso de casación. La sentencia cuenta con el voto particular de dos de los seis magistrados de la Sección Séptima de la Sala de lo Contencioso, que disienten de sus compañeros y consideran que la interpretación ahora abandonada por el Supremo -que asimilaba las RPT a disposiciones generales- era "más respetuosa con el derecho de los empleados públicos a la tutela judicial efectiva de sus derechos e intereses legítimos". Añaden que con el giro jurisprudencial que se da ahora queda excluido tanto el acceso a la casación de las sentencias pronunciadas sobre ellas, como su impugnación indirecta.

\section{CONCLUSIONES}

La Sala de lo Contencioso-Administrativo del Tribunal Supremo de 5 de febrero de 2014 (recurso núm. 2986/20129) modifica su doctrina sobre la consideración jurídica de las Relaciones de Puestos de Trabajo (RRPPT) de la Administración del Estado (AGE) y los organismos directamente dependientes de la misma. Esto supone que a partir de esta Sentencia, las RPT, serán declaradas como actos administrativos plúrimos a sensu contrario de su calificación precedente, donde su configuración y trato procesal era bajo la figura jurídica de reglamentos. Esta singularidad jurídica, no normativa, como bien se ha ido afirmando a lo largo del texto, será sólo aplicable a la Administración General del Estado u otros organismos dependientes directamente de la misma. No así sucederá con el caso de las Comunidades Autónomas y los Entes Locales, cuya figura jurídica al respecto, será la reglamentaria.

Afirma el Tribunal Supremo, inspirado en el deseo de acabar con la esquizofrenia de que una actuación jurídica puede ser acto y norma a la vez, en su Fundamento Jurídico Tercero, que "en tal sentido la función jurídica de la RPT no es la de ser norma de ordenación general y abstracta de situaciones futuras, sino la de ser un acto-condición, mediante el que, al establecer de modo presente y definitivo el perfil de cada puesto, este opera como condición y como supuesto de hecho de la aplicación al funcionario que en cada momento lo sirve de la norma rectora de los diversos aspectos del estatuto funcionarial. (...) Hemos así de conducir, rectificando expresamente nuestra jurisprudencia precedente, que la RPT debe considerarse a todos los efectos como acto administrativo, y que no procede para lo sucesivo distinguir entre plano sustantivo y procesal".

Aunque la sentencia, en cuanto a su contenido, no intenta prejuzgar su efecto en las Comunidades Autónomas es un hecho constatable que, salvo configuración normativa diferente por la ley de función pública, el cambio al considerar las RPT como simples actos administrativo tendrá una serie de consecuencias colaterales. Desde un punto de vista subjetivo, afectará de facto a todas las Administraciones Públicas y sus correspondientes RPT. Tendrán también un efecto objetivo, pues todas las casaciones pendientes en el Supremo se verán inadmitidas de forma sobrevenida. Y por último un efecto procesal pues en aquellos pleitos cuya resolución se encuentre en curso, habrá que plantearse la situación de las impugnaciones indirectas, sin que esta figura pueda ser expuesta ante el Tribunal Supremo, con la eventual necesidad posterior de acumulación objetiva de acciones, falta de celeridad en la resolución de conflictos, etc.

Por lo tanto, la Sentencia del Tribunal Supremo de 5 de febrero de 2014, es clave desde el punto de vista de la organización y del empleo público, ya que su criterio no termina con una tradición jurisprudencial, a favor de la figura del acto administrativo plúrimo, dejando la potestad reglamentaria lejos de ser objeto directo de la Administración General del Estado y sus organismos dependientes directamente de la misma, en materia de RRPPTT. 


\section{BIBLIOGRAFÍA}

- DOMINGO ZABALLOS, Manuel José (2010a) y ESCUÍN PALOP, Vicente (2010b), Impugnación y revisión de la actividad de los Entes Locales (Teoría y práctica). Pamplona, Civitas, Thomson Reuters, p. 81.

- GALÁN GALÁN, Alfredo (2010), “La consolidación del principio de vinculación negativa en el ámbito local” Revista CEMCI, nº 8, p. 20.

- JIMÉNEZ ASENSIO, Rafael (1989), Políticas de selección en la función pública española (1808-1978), Madrid, Ministerio para las Administraciones Públicas, p. 258.

- $\quad$ PAlomar OlMedA, Alberto (1996), Derecho de la Función Pública, Madrid, Dykinson, p. 168.

- PARADA, Ramón (2012), Derecho Administrativo II. Organización y empleo público. Madrid, Marcial Pons, Vigésima segunda edición, pp. 468-470.

- ROQUETA BUJ, Remedios (2012a) y SEVILLA MERINO, Ignacio (2012b), Comentarios a la Ley de Función Pública Valenciana, Valencia, Tirant Lo Blanch, pp. 253-258.

- SANCHEZ MORÓN, Miguel (2013), Derecho de la Función Pública, Madrid, Tecnos. 